\title{
What if the Role of Healthcare Was to Maximize Health?
}

\author{
Alice Hm Chen ${ }^{1,2}$ and Marshall H. Chin ${ }^{3}$ \\ ${ }^{1}$ San Francisco Health Network, Department of Public Health, San Francisco, CA, USA; ${ }^{2}$ Division of General Internal Medicine, Zuckerberg San \\ Francisco General Hospital, University of California San Francisco, San Francisco, CA, USA; ${ }^{3}$ Section of General Internal Medicine, Department of \\ Medicine, University of Chicago, Chicago, IL, USA.
}

KEY WORDS: anchor institutions; health-related social needs; population health; social determinants of health.

J Gen Intern Med 35(6):1884-6

DOI: $10.1007 / \mathrm{s} 11606-019-05524-3$

(c) Society of General Internal Medicine 2019

$\mathrm{S}$ ince the passage of the Affordable Care Act, the healthcare sector has made important shifts from a reactive, fee-for-service system to one that is accountable for health outcomes, in part by attending to issues that are not traditionally considered the purview of healthcare. Health system and payor initiatives are addressing food insecurity, transportation barriers, and housing for the homeless. Physicians, via the American Medical Association (AMA), are spearheading efforts to create additional billing codes to capture patients' health-related social needs. To support these activities, a growing number of electronic platforms are providing searchable, centralized databases of community resources, and big electronic health vendors like Epic and Cerner are actively working to integrate social care screening into their offerings. Much of this activity has been driven by payment models that demand increased accountability for the care of populations, at a time when income and wealth inequality are at historic highs. From both a fiduciary and an ethical perspective, healthcare has a responsibility to meet this demand. Others are grappling with similar imperatives. The Business Roundtable recently updated its Statement on the Purpose of a Corporation, expanding its responsibility from maximizing shareholder value to also delivering value to customers, investing in employees, dealing fairly and ethically with suppliers, and supporting the communities in which they work. ${ }^{1}$ We believe that healthcare, as one of the largest sectors in the economy, must do its part. Below we outline four areas of activity for healthcare organizations that could move us from a transactional system focused on providing and paying for healthcare services to one that could measurably improve the health of Americans.

Received September 12, 2019

Accepted October 25, 2019

Published online November 14, 2019

\section{KEEP THE MOMENTUM GOING: SCREEN AND ADDRESS INDIVIDUAL PATIENT HEALTH-RELATED SOCIAL NEEDS}

Universal screening of patients' health-related social needs with connection to community-based resources should become standard of care. In 2011, four out of five physicians in a national survey conducted by the Robert Wood Johnson Foundation believed patients' social needs are as important to address as their medical needs. Since then, much has happened to turn that belief into action. The Center for Medicare and Medicaid Innovation's Accountable Health Communities Initiative has funded 30 communities to link beneficiaries to needed community services and developed the 10-item Accountable Health Communities Health-Related Social Needs screening tool. Over half a dozen companies offer electronic platforms to connect healthcare organizations to community resources.

Earlier this year, Kaiser Permanente launched a national initiative to systematically refer its members to social service providers. Other health systems, physicians, and frontline care teams should also incorporate social service screening and referrals into their clinical workflows; better yet, they can partner across medical groups and health systems to create regional social service referral systems. Payors can accelerate adoption by investing in and incentivizing use of such systems, as well as judiciously implementing associated performance measures.

\section{PRIORITIZE THE HEALTH IN HEALTHCARE: INVEST IN SERVICES THAT ARE MOST LIKELY TO IMPROVE POPULATION HEALTH}

While connecting with community-based organizations outside the four walls of healthcare facilities is the right thing to do, opportunities also exist to intentionally invest in healthcare services that meet societal needs. Increased spending on primary care is associated with increased quality, decreased costs, and improved health outcomes, including mortality. ${ }^{2}$ Yet primary care investment is insufficient; indeed, health systems often treat primary care as a "loss leader" to channel patients into more profitable service lines. Similarly, despite the push for behavioral health parity, mental health and substance use disorder services remain inaccessible for many. According to the 2017 National Survey on Drug Use and Health, only $12.2 \%$ of Americans who needed substance use specialty treatment services received them. 
Payors have a critical role in determining which services are prioritized by delivery systems. For example, insurers have come under increased scrutiny for low payments for mental health services. In 2014, commercial payors paid an average of 13-15\% less for in-network mental health services compared to fee-for-service Medicare, despite paying 12\% more than Medicare for other services. ${ }^{3}$ The Centers for Medicare and Medicaid Services' creation of alternative payment models for primary care is a promising development, as is the recent influx of $\$ 1.4$ billion from the federal Department of Health and Human Services' State Opioid Response grants to support medication-assisted treatment. However, we still have far to go in aligning healthcare with patient and community needs. Imagine a world where we invested more in primary care, mental health and substance use services than in surgical robots of dubious value.

\section{LOOK IN THE MIRROR: IMPLEMENT ANCHOR INSTITUTION PRACTICES}

Hospitals are often the largest employer in their communities. As such, many are embracing their identity as anchor institutions: organizations that by dint of their mission, invested capital, and services are unlikely to relocate. Rush University Medical Center has published an Anchor Mission Playbook that outlines key strategies to improve the local economy and community health. ${ }^{4}$ This includes inclusive, local hiring, sourcing, capital projects, and investing practices, as well as support for affordable housing. We would add to this list organizational policies around minimum wage, sick leave and use of contract labor. Any healthcare organization committed to screening its patients for health-related social needs should also consider screening its own employees for food insecurity or being unbanked (an indicator of financial insecurity and risk for using payday lenders).

Examples of anchor institutions include organizations like Duke University Health System and Novant Health, which have increased the minimum wage for employees, thereby increasing the financial security of their surrounding communities. Dignity Health has provided loans and lines of credit at or below market rate to support small businesses, affordable housing, and healthy food projects. In Cleveland, University Hospitals, Cleveland Clinic, and Case Western were founding partners in the city's multi-sector initiative for sustainable economic development and neighborhood stability, widely known as "The Cleveland Model." Building on the commitments of anchor institutions, what might a collective Statement on the Purpose of Healthcare look like?

\section{PUT OUR MONEY WHERE OUR MOUTH IS: EXPAND THE FOCUS OF POLITICAL CLOUT}

The healthcare industry is among the most politically influential business sectors. The American Hospital Association,
Blue Cross/Blue Shield and the AMA are consistently ranked among the most prodigious spenders on federal lobbying. These efforts are typically focused on areas of clear selfinterest such as regulatory burden, reimbursement, and scope of practice issues. However, in recent years, professional organizations such as the AMA have been more vocal in supporting public health efforts such as addressing gun violence and combating the opioid crisis.

Growing recognition that issues beyond the healthcare sector impact health require an expansion of healthcare's advocacy attention. For example, the 2018 Farm Bill was recently highlighted as a "powerful, but underutilized, tool for promoting public health." 5 Encompassing $\$ 86$ billion in annual food spending, it included expanded financial incentives for Supplemental Nutrition Assistance Program (SNAP) recipients to purchase fruits and vegetables, a pilot prescription program for produce, and support for nutrition education and obesity prevention. Consider the effect on individual and community health if hospitals, health plans and physicians focused their collective political advocacy on maximizing the health impact of the Farm Bill or raising the federal minimum wage.

Ultimately, if the healthcare sector is truly serious about the health of individuals and communities, we need to consider whether we should shift resources away from healthcare into social services, in line with other industrialized countries with better health outcomes than the United States. ${ }^{6}$ The reality is, even as healthcare expands its conceptualization of health, most activity is firmly centered on addressing individual social needs rather than addressing structural social determinants of health. Referring a patient to the hospital's food pharmacy may significantly improve his diabetes and hypertension control, but does not address the fact that he and his family live in a food desert. Likewise, obtaining a rent rescue subsidy for a patient to stave off eviction does not remedy the decades-long lack of investment in affordable housing that puts her and her neighbors at risk of homelessness.

Until structural drivers of health are addressed more comprehensively, the healthcare sector can take these four actionable steps - addressing individual patients' social needs, investing in services more likely to improve population health, implementing anchor institution principles, and advocating for policies beyond healthcare that increase health - to ensure that we intentionally contribute to health.

Acknowledgements: Dr. Chin was supported in part by the Chicago Center for Diabetes Translation Research (NIDDK P3O DK092949), the Robert Wood Johnson Foundation Advancing Health Equity: Leading Care, Payment, and Systems Transformation Program Office, and the Merck Foundation Bridging the Gap: Reducing Disparities in Diabetes Care National Program Office.

Corresponding Author: Alice Hm Chen, Division of General Internal Medicine, Zuckerberg San Francisco General HospitalUniversity of California San Francisco, San Francisco, CA, USA (e-mail: alice. chen@ucsf.edu). 


\section{REFERENCES}

1. Business Roundtable. Statement on the Purpose of a Corporation Available at: https://opportunity.businessroundtable.org/ ourcommitment/. .

2. Starfield B, Shi L, Macinko $\mathbf{J}$. Contribution of primary care to health systems and health. Milbank Q. 2005;83(3):457-502.

3. Pelech D, Hayford T. Medicare Advantage and commercial prices for mental health services. Health Aff. 2019;38(2):262-267.
4. Ubhayakar S, Capeless M, Owens R, Snorrason K, Zuckerman D. Anchor Mission Playbook [Report]. Chicago, IL: Rush University Medical Center; June 2017.

5. Mozaffarian D, Griffin T, Mande J. The 2018 Farm Bill - implications and opportunities for public health. JAMA. 2019;321(9)835-836.

6. Bradley EH, Lauren AT. The American Health Care Paradox: Why Spending More Is Getting Us Less. New York NY: PublicAffairs, 2013.

Publisher's Note Springer Nature remains neutral with regard to jurisdictional claims in published maps and institutional affiliations. 